\title{
Creating Lifelong Learners: Fostering Facilitation, Modeling, \& Choice in the Classroom
}

\author{
Angela Falter Thomas ${ }^{1, *}$ \\ ${ }^{1}$ School of Teaching and Learning, College of Education \& Human Development, Bowling Green State University, \\ 529 Education Building, Bowling Green, Ohio 43403, USA \\ *Correspondence: School of Teaching and Learning, College of Education \& Human Development, Bowling Green \\ State University, 529 Education Building, Bowling Green, Ohio 43403, USA. Tel: 419-372-9546. E-mail: \\ AngThom@bgsu.edu
}

Received: June 7, 2015

Accepted: July 13, 2015 Online Published: August 6, 2015

doi:10.5430/jct.v4n2p17

URL: http://dx.doi.org/10.5430/jct.v4n2p17

\begin{abstract}
This article discusses alternatives to the lecture-style teaching that remains a fundamental practice for many middle school classrooms. Information was accumulated by pre-service middle school language arts teachers, who interviewed their mentor for their student teaching experience, focusing on how each teacher attempts to foster lifelong learning through facilitating learning rather than directing it. To do so, respondents stated that they attempt to provide more choices for students based on students' interests or experiences, promote collaboration among students, and model or guide the learning by providing clear examples. These methods of communication attempt to inspire learning with the use of visual, auditory, tactile, or kinesthetic instructional techniques. Teachers provide students with the digital environment to foster research skills, making students much more autonomous learners. It is hoped that by reading this article teachers will be able to facilitate the learning of students so as to promote students' own interests, creating lifelong learners as a result.
\end{abstract}

Keywords: student choice; alternatives to lecturing; middle school

\section{Introduction}

Lecturing, as a method of teaching, remains a fundamental practice for many middle school teachers. However, students who are in lecture-based classrooms are typically not able to see how things work, nor can they interact with the material because they are simply watching and listening, not engaging with the content or actively using their minds. John Dewey (1938) supported the process of inquiry through experimental and problem-solving learning. He appraised lecture-style presentations as an ineffective pedagogy.

\section{Hands-On, or Raise Your Hands?}

Instead of using teaching methodologies that are more engaging, many teachers are still lured into lecturing. According to Tatum (2014), classroom environments and curricula are not often structured for students. Students are not actively engaged with content and texts that they find meaningful in lecture-based classrooms; however, Fisher \& Frey (2014) inform us that we need to ensure adolescents are not denied the access to meaningful texts. To obtain inquiry and deep thinking, a teacher's role is not to provide students with answers but to facilitate by providing materials or resources to help with their questions.

Interest and motivation are vital elements in inquiry learning (Kuhlthau \& Maniotes, 2010). Students may be interested in topics relevant to current events or their own experiences. They also may be motivated when they are permitted to work with peers.

Some teachers' wrongly believe that working in groups wastes valuable class time; however, according to approximately 400 studies, cooperative learning increases student achievement and retention (Johnson \& Johnson, 2009). When students work in groups, teachers typically take the role of facilitators, modeling and guiding inquiry and exploration for their students.

As students begin to gather and analyze information, technology can serve as a groundwork for students' active construction of knowledge. We must meet students where they are. As Baldino, (2014), informs us, "Our middle 
level students are completely immersed in a tech world that is dictated by various forms of social media: Twitter, Facebook, Instagram, etc." p. 32. More specifically, skills such as smart searching with key words, accessing appropriate databases and search engines, and evaluating websites in research should be modeled (O'Hanlon, 2013).

Producing and sharing findings can be tailored to students' preferences. Some teachers may prefer publishing using a Word document and posting it to a web page. A more innovative option may be creating and sharing video online using digital tools. Lankau, Parrish, Quillin, and Schilling (2014) provide teachers and students with extremely helpful tools and a plethora of project ideas. For example, teachers may advertise with a newspaper ad/travel poster/brochure or by creating a movie box, PowerPoint or Hyperstudio slide show, or a Web page, to name a few.

Fostering inquiry and investigation can promote students to be lifelong learners. This article reports the findings of a study conducted by interviewing 31 middle school teachers on how they attempt to create lifelong learners.

\section{Methodology}

\subsection{Procedures}

The pre-service teachers in this study were middle childhood education majors soon to be licensed to teach language arts to students in grades 4-9. They were taking their final language arts course at a large state university located in the midwest. For homework, the pre-service teachers were to interview their Cooperating Mentor Teacher (CMT) about how they attempt to create lifelong learners.

After interviewing their CMTs, the pre-service teachers uploaded their CMTs responses into Qualtrics, an online survey program. Finally, they came to class to share and discuss what they learned from their CMTs.

\subsection{Participants and Settings}

The 31 pre-service teachers in this study each interviewed a practicing middle school language arts teacher who was serving as their CMT for their student teaching field experience. Table 1 provides the number of teachers interviewed at each grade level.

Table 1. Grade Levels of Cooperating Mentor Teachers (CMTs) Interviewed

\begin{tabular}{lll}
\hline Grade Level & Number of Teachers & Percentage \\
\hline $4^{\text {th }}$ Grade Teachers & 2 & $6 \%$ \\
$5^{\text {th }}$ Grade Teachers & 7 & $23 \%$ \\
$6^{\text {th }}$ Grade Teachers & 11 & $35 \%$ \\
$7^{\text {th }}$ Grade Teachers & 11 & $35 \%$ \\
\hline
\end{tabular}

Nine teachers (29\%) taught in an urban setting, 10 teachers $(32 \%)$ taught in a rural setting, and $12(39 \%)$ of the teachers taught in a suburban district. The teachers had between four and 28 years of teaching experience with a mean 15 years. All of the teachers taught in a public school.

\subsection{Data Collection}

Data, collected in the form of interview responses, were intended to capture the CMTs' perspectives on how they try to create lifelong learners in their middle school classrooms by responding to an open-ended interview question: how do you attempt to create lifelong learners? The pre-service teachers then uploaded their CMT's responses into an online data management system.

\subsection{Data Analysis}

To make sense of the data, I enlisted in the help of another researcher and together we conducted the analysis of the data uploaded in Qualtrics. We first worked separately, using selective coding to highlight the most common categories and to explain themes (Creswell, 2007). Interview responses were analyzed and salient themes were devised and integrated to support assertions. Manual coding for salient themes were informed by strategies recommended by Dyson and Genishi (2005) and Saldana (2013). Additionally, a research assistant entered the same data and used the computer software QSR NVivo9 to create categories and codes. Finally, we all three met together to discuss our results. Three dominant themes emerged: teacher facilitation of student learning (95 statements), opportunities for choice (74 statements), and teacher modeling of thinking, skills and strategies (60 statements). The data analysis allowed us to develop the assertions described in the following section. 


\section{Findings}

\subsection{Paradigm Shift: Be a Guide on the Side, Not a Sage on the Stage}

The study's respondents believed that to create lifelong learners, teachers need to shift away from directing learning to facilitating - providing guidance and scaffolding student learning. Although many stated they learned good methods for teaching in college, respondents admitted it's easy to slip into a direct-teaching mode. One participant said, "Thinking is what middle grades students are most resistant to - they want you to just give them the answer. It's easy to do that, but I must encourage my students to question what they read and to help them research the unknown even though that takes precious time and even though it feels like I'm losing some control as the teacher." On a later day the same respondent said, "I realize it is better for their learning to facilitate, not just answer. I find it best to ask open-ended questions."

According to one of the study's participants, "Lifelong learning requires developing inquiry and that stems from a student's curiosity or interest." To help students have an interest in working and to learn critically, teachers should not talk at students but instead provide meaningful circumstances to engage them and to let them work with peers in real-world situations. One respondent said, "I think it's best to show students what is going on outside of school and to help them make connections to their own lives through interesting assignments." Another said, "I keep it relevant, present material in unique and interesting ways, and pose thought-provoking questions to scaffold and guide student learning." Yet another teacher explained, "In order for me to understand something, I need a real life connection to it; therefore, I talk briefly about my own experiences, but do so in a way that appeals to students at my grade level. For example, I don't talk about planning my wedding but instead talk about planning a big project I did in school when I was their age." Learning is enhanced when students give examples, repeat the information in their own words, or make use of the information. These participants also report teachers should share with students the importance of inquiry and be structured yet flexible with their lesson plans. Collaboration should also be embraced.

When working in a mode of facilitation, teachers often guide student collaboration and use peer and cooperative learning as students work together on projects. Study participants stressed the importance of groups for students to share ideas, have rich discussions, and formulate questions, but they warned collaboration needs careful monitoring and guidance so that it is successful. One teacher explained, "Most of my sixth graders come to me without much experience in collaborating with their peers so I try to develop collaboration first with pairs doing small tasks. Then I build up to small groups. Finally, after lots of practice and seeing that my students are comfortable, focused and effective working in groups, they tackle bigger, more complex projects."

\subsection{The Choice Is Yours}

All humans need to feel as if they have control over their lives. When students are offered choices, they feel in control. One of the outcomes of offering middle school students choices is the reduction of conflict between students and teacher. When teachers direct students' behavior most of the day, the child's natural desire to be independent is thwarted and feelings of resentment or rebellion may arise (Edwards \& Watts, 2010). Additionally, choice encourages autonomy and learning. We cannot expect students to be totally independent, of course; however, making choices is part of learning, growing, and problem solving. When students have options, they expand their minds and often generate new, unique combinations of ideas.

According to the study's participants, students should choose their topics, and teachers should guide and scaffold instruction as students conduct research exploring their topics. One teacher said, "Knowing my students and their interests helps me work better. Not only can I make informed options, specifically tailored to them as individuals, but they also know I value them. That builds rapport. And because my students know I care, they are more likely to trust and ask questions while they work."

In addition to offering choice in topics, most of these teachers explained that students should also be permitted to select the ways they present and share their learning, and serving as a facilitator, instead of a director, allows them to do that. Some teachers offer choice boards, which are set up like tic-tac-toe boards and typically offer about nine different options for students to select to share their work. Other teachers use more limited choices, such as having two or three different options, whereas others utilize the sharing outlets technology offers such as blog posts and websites like Glogster and Issuu. More common suggestions from the teachers included PowerPoints, graphic organizers, skits, videos, reports, comic strips, role plays, commercials, and interviews. Some teachers suggested using Google Docs and Google Chromebooks. Other Web 2.0 tools include wikis, blogs, and video-sharing platforms to connect and provide research opportunities. Digital tools as well as face-to-face sharing of results both have positive effects. 


\subsection{Model More, Lecture Less}

Showing students what is desired is effective. The teachers felt that it is the responsibility of teachers to provide guidance and modeling. They reported that teacher modeling is memorable and more helpful than voice instruction. They explained that through teacher modeling, students are provided with clear examples of expectations, skills, and strategies. With modeling, teachers describe or show what is needed with the use of visual, auditory, tactile, or kinesthetic instructional techniques. One teacher explained, "I like to share examples, as well as non-examples, to let my students know what I am looking for, or how to do so something. The non-examples let me to show what is not acceptable without being threatening. Students often laugh, even though I know some of them would actually do that unless I shared with them in advance that wasn't acceptable." The teacher may also model with a specific example or starting prompt, or by generally speaking aloud in a form of scaffolding.

These teachers ask questions to check for student understanding by using "think alouds" throughout their modeling. Think alouds are an effective way to model so students can visualize what goes on in the teacher's mind as they are learning something new or developing understandings. One teacher said, "I use a lot of think alouds and stop frequently to get student input or ask questions. I find this provides high levels of student engagement." Another teacher explained, "So I don't come off as a 'know it all' and turn off students, I incorporate think alouds to model what I'm thinking and how I work through a problem. I say to myself, 'Now what does that word mean?' and 'Hmmm, what is the author implying?"'

Some of the study's participants shared practical items their students enjoy such as having a poster with a giant question mark on it. Students are encouraged to grab a sticky-note to write down questions they have. Another teacher said, "I have an 'Answer of the Week' poster where I put an answer to a question about language arts, and then my students have to figure out what the question is by the end of the week." Another shared, "My students like the short videos on BrainPop. After watching a video, I find we often have excellent discussions."

These teachers relayed the importance of creating a digital environment to make research easier and more autonomous for students to take the initiative to conduct their research. They stated they should show, explain, and offer students appropriate tools to explore and find answers. Giving students proper search engines, credible websites, and ways to conduct precise, safe searches are vital. Students need to know how to decide if information they find is credible, reliable, relevant, and important. One teacher said, "I need to be very basic, because they don't know how to even begin. I teach them how to determine key words or phrases to use when conducting a search." Another said, "I provide examples of plagiarism and show how to reference work using a reference page." Teachers also stressed the importance of being aware of changing sources in resources and knowing good tools to use when conducting research.

\section{Conclusions}

Providing inquiry activities that allow for groups of students to communicate, collaborate, and problem solve is a great way to facilitate and engage students in interesting learning materials, which broadens their minds and makes them want to question more. Cooperative learning can boost motivation and add variety and interest. Students' preferences can be included by allowing them to choose how they want to demonstrate their learning. This learning can be shared with the classroom as a whole or in a larger global scale online.

When teachers are directing the learning, students' brains are not effectively processing or retaining information. Students learn best when they are mentally involved and when they are involved in a process of inquiry, interpretation, investigation, and discovery. Through facilitation, modeling, and opportunities for choice, teachers can ultimately empower students to become lifelong learners.

\section{References}

Baldino, S. (2014). The classroom blog: Enhancing critical thinking, Substantive discussion, and appropriate online interaction. Voices from the Middle, 22(2), 29-33.

Creswell, J. W. (2007). Qualitative inquiry and research design: Choosing among five approaches (2nd ed.). Thousand Oaks, CA: Sage.

Dewey, J. (1938). Logic: The theory of inquiry. New York: Henry Holt.

Dyson, A.H., \& Genishi, C. (2005). On the case. New York, NY: Teachers College Press.

Edwards, C. H., \& Watts, V. J. (2010). Classroom discipline and management $\left(2^{\text {nd }}\right.$ ed). Milton, Qld: John Wiley \& 
Sons.

Fisher, D., \& Frey, N. (2014). Close reading as an intervention for struggling middle school readers. Journal of Adolescent \& Adult Literacy, 57(5), 367-376. http://dx.doi.org/10.1002/jaal.266

Johnson, D., \& Johnson, R. (2009). An educational psychology success story: Social interdependence theory and cooperative learning. Educational Researcher, 38(5), 365-379. http://dx.doi.org/10.3102/0013189X09339057

Kuhlthau, C. C., \& Maniotes, L. K. (2010). Building guided inquiry teams for 21 st-Century learners. School Library Monthly, 26(5), 18-21.

Lankau, L., Parrish, R., Quillin, L., \& Schilling, S. (2014). Research project guide: A handbook for students and teachers.

Retrieved

from http://www.commoncorehistorysocialstudies6to8.com/uploads/1/3/5/2/13524571/research_project_guide.pdf

Neo, T., Neo, M., Kwok, W., Tan, J., Chen-Haw, L., \& Embi, Z. (2012). Promoting life-long learning in a multimedia-based learning environment: A Malaysian experience. Journal of Educational Multimedia and Hypermedia, 21(2), 143-164.

O’Hanlon, L.H. (2013). Teaching students better online research skills. Education Week, 32(32). Retrieved from http://www.edweek.org/ew/articles/2013/05/22/32el-studentresearch.h32.html?tkn=QSYFO8Xjzh4fbPTZtW5v QA\%2Bc4nc964mlMo6Y\&cmp=ENL-EU-NEWS1\&intc=EW-ELDC13-ENL

Saldana, J. (2013). The coding manual for qualitative researchers. Thousand Oaks, CA: Sage.

Tatum, A. (2014). Texts and adolescents: Embracing connections and connectedness. In Hinchman, Kathleen A., and Heather K. Sheridan-Thomas, (Eds.), Best practices in adolescent literacy instruction (2nd ed.) (pp. 3-19). New York, NY: The Guilford Press. 